\title{
Transformation of Pedagogical Communicative Competence during Creation Digital Online Courses
}

\author{
Maxim L. Grunis \\ Kazan (Volga region) Federal University, Russia \\ ORCID: 0000-0002-6952-0472 \\ Inna I. Golovanova \\ Kazan (Volga region) Federal University, Russia \\ ORCID: 0000-0003-0001-3509 \\ Galiya I. Kirilova \\ Kazan (Volga region) Federal University, Russia \\ ORCID: 0000-0002-4089-9554 \\ Elena Y. Levina \\ Institute of Pedagogy, Psychology and Social Problems, Russia \\ ORCID: 0000-0002-3216-2499 \\ Zhanna M. Sizova \\ I.M. Sechenov First Moscow State Medical University (Sechenov University), Russia \\ ORCID: 0000-0002-1242-7074
}

Received: 28 Sep 2020

Accepted: 22 Nov 2020

\begin{abstract}
The purpose of this work is to identify the transformations of communicative functions. These functions are associated with the subjects of communication in both fields: in pedagogical and organizational, also in the instrumental and design once during the process of creating digital video recordings for online courses. Questionnaires, observation, and factor analysis were used as research methods. It helped to formulate a popularity rating of digital tools for future teachers. The study was conducted at the Institute of Psychology and Education of Kazan (Volga region) Federal University. The study involved 120 people: teachers developing online courses and students studying at the pedagogical educational programs. Transforming indicators of pedagogical communicative competence are highlighted. These indicators are needed to be emphasized when improving teacher training. It will help future teachers to be able to effectively carry out their activities in digital educational environment. These indicators are: the ability to organize interactive cooperation during training, the ability to organize mutual exchange and development of students, the ability to create an open environment for analysis and improvement. The methodological aspects of the development of pedagogical communication functions in the dynamic environment of digital education and an interactive environment are disclosed on the basis of work with videos. Some recommendations for future teachers' skills improving and development of training experience organization in the digital environment are given. These are a clearly-setgoal for educational video materials, adequate video content, skills for digital tools using, also the skill to choose adequate digital tools for a task fulfillment. The tool that can enhance enthusiasm, and stimulate students for productive work in a digital environment. The study allows improving video content and increasing the effectiveness of its use in the educational process. Also, the results of the experiment can become a basis for teacher training programs improving. Especially it can be useful for future teachers' pedagogical communicative and digital competences development. The tasks developed within the frame of the research will be included in the assignments of pedagogical internship for pedagogical Master's degree courses at the Institute of Psychology and Education of Kazan Federal University. These tasks for students include development and use of online courses with video materials.
\end{abstract}

Keywords: pedagogical communicative competence, digital educational environment, digital video recordings, educational videos, online courses 


\section{INTRODUCTION}

The current situation with the Coronavirus pandemic create conditions for urgent operational task for educational institutions - to switch to a new format - a remote or distance teaching. In this situation the relevance of this study is highly increasing (Bubnova et al., 2018; Kardis et al., 2019; Mulenga \& Marbán, 2020; Castro et al., 2020). The educational information transfer and receipt in the form of lectures, instructions, and videos, has become one of the basic processes in the training system today (Biswas et al., 2020; Cahapay, 2020; Demuyakor, 2020; Lounis, 2020; Min \& Nasir, 2020; Salame \& Hanna, 2020; Sintema, 2020). New tasks require a transformation of teachers' competencies. Particular attention requires pedagogical communicative competence, which is based on the ability of a teacher to organize information in a new digital format in the process of digital educational videos creation.

During the process of post-industrial society forming, communicative competence acquires special features and significance. In this process information is one of the most important values and a means of goals achieving. The main efforts of society members are aimed at obtaining, processing, and using information, including in the process of interaction (Firsova et al., 2018; Rassolov et al., 2020). In the current situation related to the switching of education to distant learning format, the communicative competence of the teacher has become in special demand. The emphasis shifts from the organization of effective interaction of students in the audience to the organization of the educational process in the online format, where it becomes more important to convey the necessary information and track the student's adsorbing new information for using it further in his independent work. The modern digital educational environment is very dynamic, it provides a constantly updated set of tools for pedagogical communication. The educational information is being transferred and receipted in the form of lectures, instructions, and videos. It has become one of the basic processes in the training system today during the Coronavirus pandemic. This process is based on the teachers' communicative competencies in combination with their digital skills (Piralova et al., 2020; Zyubina et al., 2019). Nowadays there is a fairly large number of video sources, that contain a demonstration of different educational activities. We are talking about the use of digital videos, as well as about students who not only watch videos and get information but also try to assimilate it, organize it, and put it into practice. The pedagogical specificity of digital videos usage seems important. The future teacher who watches these videos should also be able to combine various components of his activity. For example, prepare a systematizing theoretical material in advance, think about a motivating block, emotionally convey information to the student, demonstrate the necessary practical experience.

Even though it seems quite simple to work on a computer with instructional videos, it is highly important that make sure that students use active interaction rather than passive perception. It's necessary to organize mutual information exchange between students and their mutual development. The prepared digital materials are supposed to be open for analysis and improvement. It is important to acquire not only subject knowledge but also the ability to use digital tools and develop skills to record video materials, that are useful from a didactic point of view. These future teachers' skills are supposed to develop in the process of educational video information absorbing.

\section{LITERATURE REVIEW}

A teacher needs new pedagogical competencies related to digital literacy competencies to create a modern digital educational environment (Bayanova et al., 2019; Makarova et al., 2019; Markless, 2009). Communicative competences take an important place in this case. An intelligent digital educational environment is a new trend in the development of digital learning (Huang, Yang, \& Hu, 2012). It should motivate students for problem-solving learning and create situations for active mental answers search. The development of students' creative abilities in a digital educational environment is supposed to be one of the teachers' aims (Bąk et al., 2019; Craft, 2010; Orekhovskaya et al., 2019; Zyubina et al., 2019). An important component of the digital educational environment is the online courses that are actively used today in higher education. These courses are used as an independent educational format and as a method in blended learning. It is a common mandatory standard for open online- courses (Vai \& Sosulski, 2015) to include the video content. (Cooper \& Sahami, 2013). An analysis of the work on creating and using videos for online 
courses shows the relevance of this issue to the pedagogical community. Holtzblatt and Tschakert (2011) tell that using videos within the frame of the educational process can help to expand educational opportunities and allows avoiding the restrictions of only classroom communication. B. Calandra and P.J. Rich (2014) have expressed their opinions regarding the use of videos in teaching. They suppose it will become the dominant digital tool. Rickard, McAvinia, and Quirke-Bolt (2009) consider teaching future teachers by creating and using video resources as part of a constructive approach. Brunvand's (2010) article reviewed methodological guidelines for creating teacher training videos based on best practices. K. Burden and S. Atkinson (2008) conducted a study on the effective use of digital video in higher education environment. Also, Blomberg et al. (2014) presented an analysis of using of videos as a tool for educators teaching and a reflection of a "development" strategy. McGarr (2009) provides an overview of video lectures (podcasts) and their use in education, as well as their impact on traditional learning. He discusses some questions regarding the topic if videos can help to solve some higher education problems in terms of academic performance and if podcasting worth the investment. To find answers for these questions the author examines the vast array of scientific literature published in 2004-2009 devoted to the experience of video-making for higher education purposes. The author comes to the conclusion that purely in terms of assessing student performance, the podcasting effectiveness is still rather weak. It is also proved by a few number of parallel research in general (Khairullina et al., 2020). Nevertheless, it is believed that podcasting has several positive effects on the academic environment. One of these effects is openness to experimentation with known forms of learning. Also podcasts can help real improvement in the learning environment in case this tool is rationally used as an additional one with other learning activities. It was important to consider the concept of the dynamics of the development of video for the research organization. In the other words, it was necessary to analyze the dynamics of educational videos and the dynamics of communication, as well as teaching communication itself. Our position and understanding of the term "dynamics" was based on a study of publications in this area. The position is described in Wickelgren's (1977) work: "dynamics" is observed as a form of universal position and it is revealed through a range where a significant compromise between speed and accuracy can be achieved. We also consider the dynamics with respect to time cycles. What are the speed changes? What is the length of dynamic change cycles? What is the duration of each dynamic change cycle and what is its time ratio? And, finally, we are investigating the metadynamics concept, which is analyzed here in two directions: a) globally speaking, it is dynamics including the fundamental, most significant changes and laws that these changes are subjected to. These laws have yet to be investigated in the pedagogical aspect, $b$ ) in the narrow sense, this is the dynamics of descriptions or the dynamics of metadata. So here we are talking about leading characteristics changes. Also, we consider not only changes in the values of certain metadata indicators, but also a change in the list of these indicators.

Taking into consideration the mentioned understanding of the basic term "dynamics", we consistently consider the designated positions. We analyze the development of video records from the perspective of the historical process. It allows clearly demonstrate the transition to understanding the modern dynamics of educational videos.

Considering the history of the information transition with the help of images, it should be noted that the first images, which are known to mankind, are rock paintings. Their main qualitative characteristics of them are schematics, understanding of images, the reliability of "information carriers". Then we can mark the author's works of painting art. These images also have characteristics - schemes and understanding of images, reliability of "information carriers. Also, in this case, we should talk about the author's position and tools and technologies. The transition to video followed the corresponding invention, which conveyed the moving nature of images. Video was complemented by sound and color later.

Educational videos are created with the help of the same techniques that characterize video shooting for other purposes. Though using these techniques is not completely mastered in the educational field. The idea of saving and codifying diagnostic data to facilitate the analysis of the educational dynamics process is an object of investigation for the present research (Kolgatin, 2016). It is noteworthy that modern images and videos do not lose these characteristics. Note that the broadcast video is multidimensional. The lecturer filmed in the video not only conveys a specific text, but the lecturer also accompanies the presentation with 
his emotions, uses his energy to convey his position. He broadcasts the attitude to this text, applies pedagogical skills and oratorical experience to hold attention. The video is also multifarious. It can display fragments of systematic information, it can have background music or other sounds, or it can be in a presentation form. Also it can show posters and diagrams placed on the walls of the office, or it can present illustrations and formulas from a book or article.

At the same time, we sought to limit the number of basic characteristics. Gradually some techniques have become rather widely used for video shooting: a) orientation to the near, middle and far plans, each of them is quite clearly normalized, b) also constant plan changes are used at intervals that are multiples of four seconds, for example. As a result, we get a double effect: an active image, on the one hand, and the subsequent installation convenience, on the other hand.

Considering the dynamics of communication and communication training, we relied on the problems of group dynamics (Xin \& Feenberg, 2006), which goes through the usual stages of acquaintance. These stages are the testing partners' friendliness; a dialogue developing, communication style. The process of communication is built on these terms and it doesn't reduce to a logical system but it is based on a psychological and pedagogical model. Our study emphasizes the importance for a teacher to be heard, as well as to be correctly understood by students, as students are supposed to include the received information into their system of actively used knowledge and experience.

In the process of human development, the perception of paintings and books precedes the ability to distinguish text. However, the first training videos do not always effectively convey the contained information. The most significant reason for that was the lack of operational feedback and the loss of attention to the proposed film. Indeed, the teacher constantly changes the pace and intonation in his lecture to make it easier for understanding. The literature describes the possibilities of subtle recognition of facial expressions, which contributes to a better understanding of the relationship between posture and facial movement dynamics. It is connected with the continuous development of emotionally capable systems. Thus, we note that it is necessary to take into account the audience's reaction to both personal contacts with the lecturer and his work, presented in the video format. We are talking about feedback, which is based on continuous interactive communication, directed to the screen on the one hand, and to the audience on the other hand. It is proposed to use an additional video camera, which is filming the viewers. It can provide a lot of useful information that allows you to evaluate and improve training videos, as well as quickly respond to the audience state. At the same time, several values are supposed to be recorded. There are among them: the total number of viewers, their activity and mobility, their emotional condition (the ratio of "funny" and "sad" viewers), noise in the audience, timely reaction (for example, to a request to raise a hand and ask a question) including fixing specific phrases expressed by the audience. Such information can be used personally by the author of the training video or by an expert. It is important for further improvement of the educational process based on mutually interactive communication. The feedback assessment for course improvement was noted in the works of Petrides et al. (2008).

\section{MATERIALS AND METHODS}

\section{Study Purpose}

The research aims to identify the transformations of communicative functions associated with the subjects of communication both in the pedagogical, organizational and also in the instrumental and design spheres when creating digital video recordings for online courses. The research can help to improve the teachers' training methods. It allows students to develop their skills and to learn to carry out their activities in a digital educational environment effectively. It provides information on existing trends in the field of video production and taking into account personal students' characteristics (current knowledge, motivation, etc.). 


\section{Methods and Techniques}

Theoretical and experimental analysis of the dynamics of future teachers' communicative competence was applied to demonstrate the dynamic and productive progress in various fields of communication and various areas connected with the educational video production process. A qualitative assessment of the dynamics of the communicative functions associated with the subjects of communication took place. It was conducted both in the pedagogical and organizational and also in the instrumental and design spheres. We also used a kind of dialogue where the displayed actions serve as an example for the subsequent development of functions. The student carefully observes and studies these actions. In this case student's implementation of the mastered functions is students' own communication response. Meanwhile, the expert records the indicators demonstrated by the student in the course of the experiment. The expert estimates the indicators according to the map of the dynamics of communicative competence, developed for this study.

The main methods of this study included: questionnaires, observation and factor analysis. The factor analysis was used to form the popularity rating of future teachers' digital instruments. 120 teachers and students took part in the educational experiment. The participants mastered various fields. Thus, it becomes possible to identify the basic laws of the readiness formation for the creation and experimental use of educational videos.

\section{Research Experiment Facilities}

The experimental base of the study included teachers and students of the Institute of Psychology and Education of Kazan (Volga region) Federal University. The study involved 120 participants. There were 10 teachers and 90 students of pedagogical masters' degree courses of full-time and part-time forms of study. In particular, there were 30 people studied IT, 40 people had a humanitarian profile, and 20 people studied natural sciences. The experiment was attended by teachers and students, who had been recording videos for online courses at the KPFU studio as part of the study of the discipline "Information Technologies in Professional Activities". The study also involved 20 undergraduate students learning "the primary education" course, it’s a profile № 44.03.01. These students took part in recording videos with their teacher.

The course "Information Technologies in Professional Activities" helps future teachers to develop the competencies necessary for creating and applying educational videos in their professional teaching activities. Within the study course, the participants were divided into two groups - experimental and control. The experimental group included students who preferred to work with video information. The control group consisted of students who preferred to work with textual information.

\section{Experiment Stages}

The experiment included 3 stages.

At the first stage, the teacher - "a subject of the digital environment No. 1" develops and conducts a lecture, shoots a video for his lecture. Then the teacher gives instructions to students to prepare their videos, following the content and communication (interactions) requirements. Students get a task to shoot video following some requirements about its content and communication sources - the video which would transmit knowledge about digital tools usage for a video production.

At the second stage, the video prepared by the teacher or students becomes "a subject number 2" (agent) of the digital environment. The teaching functions are transferred to this agent. Students receive knowledge about the material structuring, and about the tools used in the implementation of the video, during the process of watching the video.

At the third stage, students - "a subject No. 3" interacted with each other while they were creating their videos, watching and evaluating the video (in the organizational and pedagogical sphere) and in the process of creating the video (in the instrumental and design sphere). 


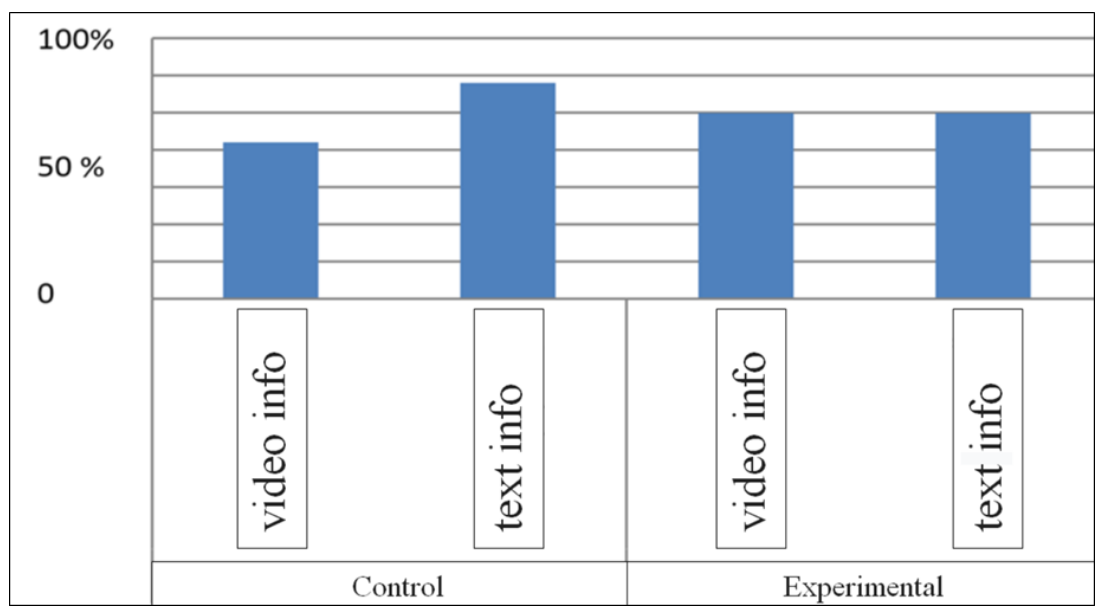

Figure 1. Preferred information type in control and experimental groups (percentage)

In the experimental group, students were invited to use not only direct but also contextual communication, while working on their videos. (One of the examples of contextual communication is the didactic role of the near and far shots in their educational videos).

At all stages, a qualitative and quantitative analysis of educational materials and educational results, as well as questionnaire and observation methods were used.

\section{RESULTS AND DISCUSSION}

We examined the dynamics of changes in indicators characterizing communicative competence in the course of the research. We highlighted the characteristic features in the indicators changes at the different stages of the educational video implementation. Also, we determined transformations in the teachers' communicative competence. We examined competencies that indicate teachers' readiness for effective work in the online format in the nearest future.

The study participants were divided into groups according to their preferred types of information - video information or textual information.

It was determined that during the experiment the participants' preferences have changed - more traditional preference to work with text information for control and the experimental groups turned to be equally text and video information preferable for both groups within the course of the experiment.

An assessment of students of the control and the experimental groups was carried based on the developed diagnostic map. The following parameters were assessed:

1) preference to get information in a video format,

2) having experience in creating videos,

3) having a desire to create educational video materials themselves,

4) having the skills to use and awareness about the techniques and tools for creating educational videos. 


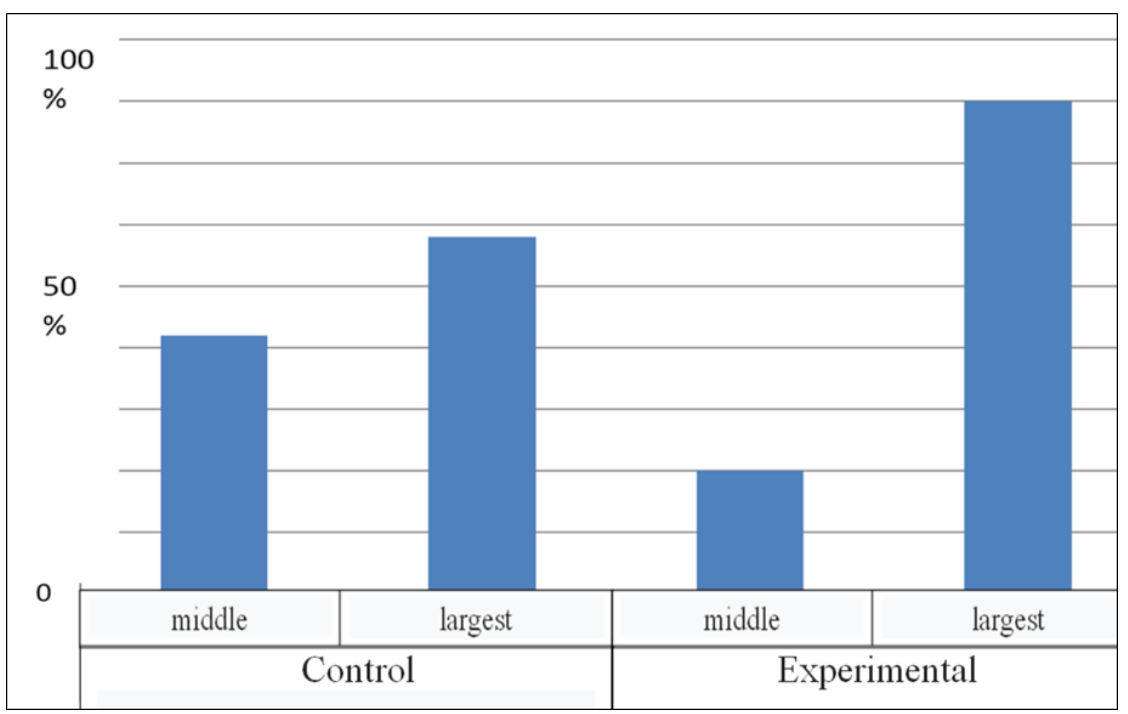

Figure 2. Dynamics of measurable factors in relation to the educational video recordings in the control and experimental groups (percentage)

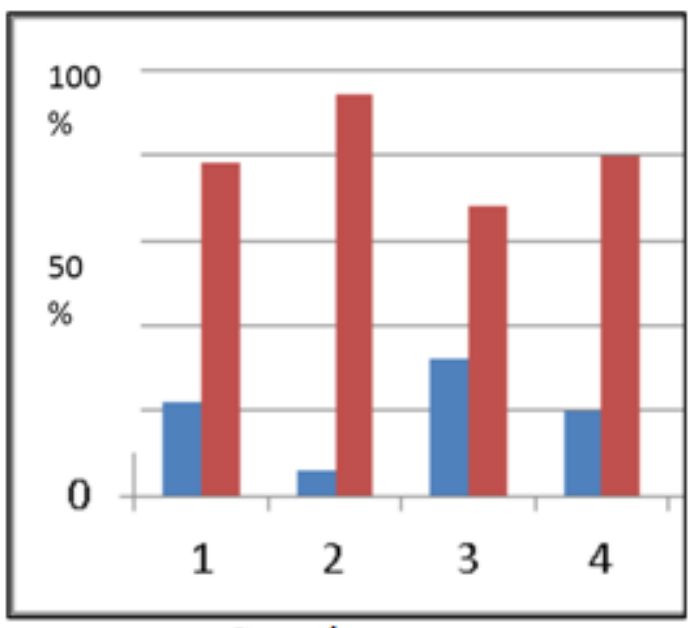

Control group

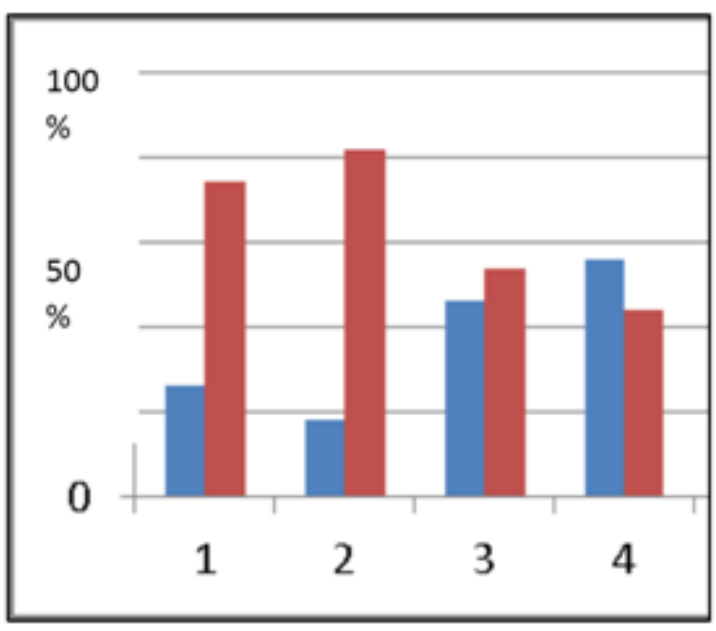

Experimental group

Figure 3. The level of skills of the video recording and tools awareness development in the control and experimental groups (percentage)

It should be noted that the greatest changes in the experimental group compared with the control group are due to factors associated with the desire to create students' videos and the possession of the appropriate tools.

Let us present the level of changes in the development of skills of using tools for working with video materials (Figure 3).

The results show a change in this level from $48 \%$ in the control group to $80 \%$ in the experimental group, which is a statistically significant result according to the chi-square criterion.

A qualitative analysis of the diagnostic card developed for the experiment, allowed us to highlight the main aspects of teacher's activities during the teaching students to create educational videos, which were connected with interactions with students in the process of video materials creation, and the desire to use and improve it. It was revealed that communications in the process of creating and evaluating videos open up new opportunities for using digital tools.

The videos on the transfer of experience are becoming increasingly popular among the work of our students. These videos demonstrate ways to create online courses. The training activity in preparing videos is not just 
a requirement and a demand of time, but also it is an opportunity to develop and improve future teachers' digital skills in real practice. Once you shoot a useful educational video, you can recommend it to students, and use it for teaching purposes.

Creation of the educational videos bank is our task for the nearest future.

At the same time, we tried to collect information on the results of work with digital resources and analyze it. Also, we used this analysis for improving and selecting videos that are consistent with specific learning goals and objectives and characterizing the participants in the educational process. In order to master more complex tasks, it is necessary to choose an effective scenario automatically. The choice should be based on an analysis of previous experience collected in the information space.

Thus, there is a cumulative interaction of communication mechanisms. It includes:

- perception of new information;

- creation of a new environment;

- systematization of previous representations through a new experience.

All of this can be implemented based on various channels of perception and communication.

The parallel execution of various actions is an important skill for future teachers. The teacher can talk about some experience or experiment, can show a diagram and demonstrate the experience effectiveness in his video. The teacher tells about some topic and shoots it all on video himself.

Students learn to make educational videos while watching training videos. Also, these students usually strive to combine the various functions of their activities. Such work requires preliminary preparation of systematized theoretical material and the selection of emotionally motivating techniques. It's necessary to explain it to other students and to show the actions combined in the video as a holistic statement. The teacher should take care of sharing video processing experience with his students. It can be a kind of metafilm (a film about the film).

A student watching this video will get an idea about the stages and the main elements of video processing.

We are currently in the process of digital space development. At the same time, a large amount of useful information about the educational process is accumulating in this space. All this is implemented with the help of various channels of perception and communication.

Firstly, it is the level of assimilation of the provided information and the relationship of this level with any of reporting methods. There are things to consider if we are talking about specific party of this system (students). All students have different levels of skills development and different interests. In this case, we recommend a very specific digital resource for each course to be used in the future.

We are talking about the consistent and systematic system controls creation and about choosing the best resource selection strategy. It will depend on which category or level a particular student will be assigned to. By analyzing the history of education in your professional field it's possible to come to a conclusion which paths were successful in the past and what methods to recommend to a particular student in the future.

It is important to note the following:

- firstly, interactive collaboration,

- secondly, mutual exchange and development,

- thirdly, openness to analysis, and improvement.

Let us show its dynamic connection with the development of communicative competence. The emphasis is connected with the process of preparing and using digital video. Videos were informative and tended to have 
only a small fraction of interactive tendencies in the past. This experiment outlined a significant positive shift in this direction:

- transition to the concept of control points that complement the previously created videos, allowing to use analytical tools.

- collected factual information will become the basis for a self-learning expert system, where the most popular questions for the automated actions of the system will be gradually developed.

- delayed interactions and active interactions are important. Speaking of delaying, we mean that the student can receive answers to their interactive learning steps selected by other students. He can take into account the questions asked by students in the previous stages and answer them.

- activity of students in a group can be taken into account when working with video. This is important for the development and further expansion of the educational video functions.

To improve the video material and increase its effectiveness in the educational process, we also suggest using an additional video camera that records viewers. It can provide a lot of useful information that allows us to evaluate and improve educational videos, and also quickly respond to the state of the audience. At the same time, the following values are subject to fixation: the total number of spectators, their activity and mobility, their emotional condition (the ratio of "funny" and "sad" spectators), noise in the audience, timely reaction, for example, to a request to raise a hand and ask a question ( including fixing specific phrases expressed in the audience).

In the course of our work on creating educational video resources at the Institute of Psychology and Education of Kazan Federal University, we tried to collect information on the results of work with digital resources in Russia and abroad and analyze it. Also, we used this analysis for improving and selecting videos that are consistent with specific learning goals and objectives and characterizing the participants in the educational process. In order to master more complex tasks, it is necessary to choose an effective scenario automatically. This choice is supposed to be based on an analysis of previous experience collected in the information space.

We propose to include tasks on the development and use of online courses with video materials as tasks for pedagogical internship for the masters' degree course at the Institute of Psychology and Education of Kazan Federal University. We suppose that it will be very useful for improving future teachers' pedagogical communicative and digital competencies.

The study of psychological and pedagogical literature allows us to state a small number of studies devoted to the problem of development of pedagogical competencies associated with the creation and work in a digital educational environment. There are some attempts to present the competencies necessary for a new teacher in a new school. The competences are observed from the perspective of various participants in the educational process and discussed in the article by Donetskaya, Golovanova, and Singatullova (2017). Attention is paid to determining diagnosable indicators for competencies development during studying the module of the master's program (Asafova \& Golovanova, 2017). Also, a system for assessing competencies formed during the pedagogical internship for a masters' degree course is observed in the works (Golovanova, Telegina, \& Doneckaya, 2019).

\section{CONCLUSION}

The theoretical part of the research revealed the current development of the digital environment requirements. The students, future teachers, are supposed to have interaction skills for communication with other students, but also they have to acquire new competencies related to the creation of educational videos. Also, they need to have knowledge about video processing tools and the theoretical foundations of video production. Though, these topics are not included in the curriculum. 
Considering the transforming indicators of pedagogical communicative competence, which should be emphasized when improving teacher training courses. It's necessary to teach a student to carry out his activities effectively in a digital educational environment. We can distinguish the following competences: the ability to organize interactive cooperation during training, the ability to organize mutual exchange and student development, the ability to create an open environment for analysis and improvement.

The research work revealed the dynamic cyclicity and activation of each of the communicative competence components. It became noticeable during the information interaction of the educational process subjects. It requires digital tools using and demonstration of professionally significant functions when creating a video. The methodological aspects of the functions of pedagogical communication development in the dynamic environment of digital education are disclosed in the present study.

It is important to highlight the openness of this system. Therefore, it is possible to confirm that every future teacher (student) can create an alternative video based on existing materials. At the same time, the rest of the participants in the educational process will be invited to review and evaluate the created educational materials. Also, it's important to note the reasons for creating alternative videos. A video devoted to the most difficult topics helps a student to understand these topics better. Thus, for a better revision of the topic, the student acts in a new role and, therefore, better assimilate it. Such videos provide specific information. The student can indicate that this is a training video, and it is not better than the main one. Thus, another function and other metadata will be placed in the video. These additional videos will be shared with educational communities for a review. The best examples, chosen after the analysis should be considered as a material for further course improvement

\section{Limitation and Study Forward}

The study was conducted only in one Russian university - Kazan (Volga region) Federal University.

\section{ACKNOWLEDGEMENTS}

1. The work is performed according to the Russian Government Program of Competitive Growth of Kazan Federal University

2. The publication has been supported by the 'Russian Academic Excellence Project $5-100$ ' of the I M Sechenov First Moscow State Medical University (Sechenov University).

\section{REFERENCES}

Asafova, E., \& Golovanova, I. (2017). Competence Approach in Teacher Training in The Process of Development and Testing of the Module «Interaction of Educational Relations participants. The European Proceedings of Social \& Behavioural Sciences EpSBS, 29, 74-82. https://doi.org/10.15405/epsbs.2017.08.02.10

Bąk, T., Kardis, M., Valco, M., Kalimullin, A. M., \& Galushkin, A. A. (2019). A philosophical-sociological diagnosis of youth subcultures in the context of social changes. XLinguae, 12(2), 163-185. https://doi.org/10.18355/XL.2019.12.02.14

Bayanova, A. R., Vodenko, K. V., Sizova, Zh. M., Chistyakov, A. A., Prokopiev, A. I., \& Vasbieva, D. G. (2019). A philosophical view of organizational culture in contemporary universities. European Journal of Science and Theology, 15(3), 121-131.

Biswas, B., Roy, S. K., \& Roy, F. (2020). Students Perception of Mobile Learning during COVID-19 in Bangladesh: University Student Perspective. Aquademia, 4(2), ep20023. https://doi.org/10.29333/aquademia/8443 
Blomberg, G., Sherin, M. G., Renkl, A., Glogger, I., \& Seidel, T. (2014). Understanding video as a tool for teacher education: Investigating instructional strategies to promote reflection. Instructional Science, 42(3), 443-463. https://doi.org/10.1007/s11251-013-9281-6

Brunvand, S. (2010). Best practices for producing video content for teacher education. Contemporary Issues in Technology and Teacher Education, 10(2), 247-256.

Bubnova, I. S., Khvatova, M. A., Chernik, V. E., Popova, O. V., Prokopyev, A. I., Naumov, P. Yu., \& Babarykin, O. V. (2018). Research of Professional Activity Features of Ecologist at Carrying Out Public Ecological Examination. Ekoloji, 106, 999-1006, Article No: e106183.

Burden, K., \& Atkinson, S. (2008). Beyond Content: Developing Transferable Learning Designs with Digital Video Archives. In EdMedia+ Innovate Learning, 4041-4050. Association for the Advancement of Computing in Education (AACE). Chesapeake: AACE.

Cahapay, M. B. (2020). Rethinking Education in the New Normal Post-COVID-19 Era: A Curriculum Studies Perspective. Aquademia, 4(2), ep20018. https://doi.org/10.29333/aquademia/8315

Calandra, B., \& Rich, P. J. (2014). Digital video for teacher education: Research and practice. London: Routledge. https://doi.org/10.4324/9781315871714

Castro, W. F., Pino-Fan, L. R., Lugo-Armenta, J. G., Toro, J. A., \& Retamal, S. (2020). A Mathematics Education Research Agenda in Latin America Motivated by Coronavirus Pandemic. Eurasia Journal of Mathematics, Science and Technology Education, 16(12), em1919. https://doi.org/10.29333/ejmste/9277

Cooper, S., \& Sahami, M. (2013). Reflections on stanford's moocs. Communications of the ACM, 56(2), 28-30. https://doi.org/10.1145/2408776.2408787

Craft, A. (2010). Creativity and Education Futures: Learning in a Digital Age. London: Trentham Books Ltd.

Demuyakor, J. (2020). Coronavirus (COVID-19) and Online Learning in Higher Institutions of Education: A Survey of the Perceptions of Ghanaian International Students in China. Online Journal of Communication and Media Technologies, 10(3), e202018. https://doi.org/10.29333/ojcmt/8286

Donetskaya, O. I., Golovanova, I. I., \& Singatullova A. A. (2017). New teacher for a new school: participants of educational process on the problem. The European Proceedings of Social \& Behavioural Sciences EpSBS, 29, 254-264. https://doi.org/10.15405/epsbs.2017.08.02.31

Firsova, I., Vasbieva, D., Prokopyev, A. I., Zykin, E. S., \& Matvienko, V. V. (2018). Development of consumers' behavior business model on energy market. International Journal of Energy Economics and Policy, 8(4), 227-233.

Golovanova, I. I., Telegina, N. V., \& Doneckaya, O. I. (2019). Podgotovka k professionalnoy deyatelnosti budushhego pedagoga na osnove razrabotannoy sistemy ocenki sformirovannosti kompetenciy. Obrazovanie i samorazvitie, 1, 58-68.

Holtzblatt, M., \& Tschakert, N. (2011). Expanding your accounting classroom with digital video technology. Journal of Accounting Education, 29(2-3), 100-121. https://doi.org/10.1016/j.jaccedu.2011.10.003

Huang, R., Yang, J., \& Hu, Y. (2012). From digital to smart: The evolution and trends of learning environment. Open Education Research, 1(1), 75-84.

Kardis, M., Sturak, P., Králik, R., Trong, D. N., Korzhuev, A. V., \& Kryukova, N. I. (2019). A sociological-religious probe into contemporary global salafi jihadism. European Journal of Science and Theology, 15(4), 113125. 
Khairullina, E. R., Shubovich, M. M., Bogdanova, V. I., Slepneva, E. V., Mashkin, N. A., \& Rodyukova, T. N. (2020). Modern student youth civic identity: Political activity or social responsibility? Opcion, 36(Special Edition 27), 1703-1717.

Kolgatin, O. (2016). Dynamics of views on ethics of pedagogical diagnostics in information and communication learning environment. Information Technologies in Education, 29, 7-14. https://doi.org/10.14308/ite000608

Lounis, M. (2020). Promoting School Health Education: A Lesson from the COVID-19 Pandemic. Contemporary Mathematics and Science Education, 1(2), ep20009. https://doi.org/10.30935/conmaths/8579

Makarova, E. V., Kryukova, N. I., Sizova, Z. M., Grinenko, A. V., Erofeeva, M. A., \& Bukalerova, L. A. (2019). Divergence of supreme values of Russian world and western civilization social and philosophical analysis. European Journal of Science and Theology, 15(3), 97-107.

Markless, S. (2009). A new conception of information literacy for the digital environment in higher education. Nordic journal of information literacy in higher education, 1(1), 115-128. https://doi.org/10.15845/noril.v1i1.17

McGarr, O. (2009). A review of podcasting in higher education: Its influence on the traditional lecture. Australasian journal of educational technology, 25(3), 63-75. https://doi.org/10.14742/ajet.1136

Min, H., \& Nasir, M. K. M. (2020). Self-Regulated Learning In A Massive Open Online Course: A Review of Literature. European Journal of Interactive Multimedia and Education, 1(2), e02007. https://doi.org/10.30935/ejimed/8403

Mulenga, E. M., \& Marbán, J. M. (2020). Prospective Teachers' Online Learning Mathematics Activities in The Age of COVID-19: A Cluster Analysis Approach. Eurasia Journal of Mathematics, Science and Technology Education, 16(9), em1872. https://doi.org/10.29333/ejmste/8345

Orekhovskaya, N. A., Chistyakov, A. A., Kryukova, N. I., Krokhina, J. A., Ospennikov, Y. V., \& Makarova, E. V. (2019). Orthodoxy and modernity their contact facets in Russian society. European Journal of Science and Theology, 15(2), 67-77.

Petrides, L., Nguyen, L., Jimes, C., \& Karaglani, A. (2008). Open educational resources: inquiring into author use and reuse. International Journal of Technology Enhanced Learning, 1(1-2), 98-117. https://doi.org/10.1504/IJTEL.2008.020233

Piralova, O. F., Gerasimenko, S. A., Kuznetsov, V. V., Popova, O. V., Subbotin, G. V., Kolomyts, O. G., \& Mashkin, N. A. (2020). Gaming Industry Trends in new Generation Specialist Training in University Environment. Journal of Environmental Treatment Techniques, 8(3), 1132-1135.

Rassolov, I. M., Chubukova, S. G., Mokhov, A. A., \& Shagieva, R. V. (2020). Genetic information and personal data under conditions of digital transformation. International Journal of Psychosocial Rehabilitation, 24(7), 284-292.

Rickard, A., McAvinia, C., \& Quirke-Bolt, N. (2009). The challenge of change: Digital video-analysis and constructivist teaching approaches on a one-year preservice teacher education program in Ireland. Journal of Technology and Teacher Education, 17(3), 349-367.

Salame, I. I., \& Hanna, E. (2020). Studying the impact of online homework on the perceptions, attitudes, study habits, and learning experiences of chemistry students. Interdisciplinary Journal of Environmental and Science Education, 16(4), e2221. https://doi.org/10.29333/ijese/8543

Sintema, E. J. (2020). Effect of COVID-19 on the Performance of Grade 12 Students: Implications for STEM Education. Eurasia Journal of Mathematics, Science and Technology Education, 16(7), em1851. https://doi.org/10.29333/ejmste/7893 
Vai, M., \& Sosulski, K. (2015). Essentials of online course design: A standards-based guide. London: Routledge. https://doi.org/10.4324/9781315770901

Wickelgren, W. A. (1977). Speed-accuracy tradeoff and information processing dynamics. Acta psychologica, 41(1), 67-85. https://doi.org/10.1016/0001-6918(77)90012-9

Xin, C., \& Feenberg, A. (2006). Pedagogy in cyberspace: The dynamics of online discourse. International Journal of E-Learning \& Distance Education/Revue internationale du e-learning et la formation à distance, 21(2), 1-25.

Zyubina, I. A., Dzyubenko, A. I., Borisenko, V. A., Popova, O. V., \& Prokopyev, A. I. (2019). Implicit linguopragmatic strategies of speech behavior of English-speaking prosecutors. XLinguae, 12(4), 92102. https://doi.org/10.18355/XL.2019.12.04.08

Correspondence: Maxim L. Grunis, Lecturer of the Institute of Psychology and Education, Kazan (Volga region) Federal University, Kazan, Russia. E-mail: max0108@yandex.ru 